\title{
A Novel Powered Nasal Irrigation After Endoscopic Sinus Surgery in Patients With Chronic Rhinosinusitis: A Preliminary Study
}

\author{
Ki-Il Lee ${ }^{1} \mathbb{D}$, Jong-Yeup Kim ${ }^{1,2}$, Sumin Son ${ }^{1}$, Seung Ho Kim ${ }^{1}$, \\ Myeong Hee $\mathrm{Kim}^{1}$, Eunwoo $\mathrm{Nam}^{3}$, and Seung Min $\mathrm{In}^{1}$ (D) \\ ${ }^{1}$ Department of Otorhinolaryngology-Head and Neck Surgery, ${ }^{2}$ Biomedical Informatics, Konyang University College of Medicine, \\ Daejeon; and ${ }^{3}$ Department of Global Health and Development, Graduate School, Hanyang University, Seoul, Korea \\ 비부비동염 환자에서 부비동 내시경 수술 후 자동형 코세정기의 유효성: 예비 연구 \\ 이기일 ${ }^{1} \cdot$ 김종엽 $^{1,2} \cdot$ 손수민 $^{1} \cdot$ 김승호 $^{1} \cdot$ 김명희 $^{1} \cdot$ 남은우 $^{3} \cdot$ 인승민 $^{1}$ \\ 건양대학교 의과대학 ${ }^{1}$ 이비인후과학교실, ${ }^{2}$ 정보의학교실, ${ }^{3}$ 한양대학교 대학원 국제의료개발학과
}

\author{
Received April 29, 2021 \\ Revised September 18, 2021 \\ Accepted October 5, 2021 \\ Address for correspondence \\ Seung Min In, MD, PhD \\ Department of Otorhinolaryngology- \\ Head and Neck Surgery, \\ Konyang University \\ College of Medicine, \\ 158 Gwanjeodong-ro, Seo-gu, \\ Daejeon 35365, Korea \\ Tel $+82-42-600-9215$ \\ Fax $+82-42-600-9090$ \\ E-mail ismi96@hanmail.net
}

Background and Objectives We aimed to compare the efficacy of a novel powered irrigation system with that of the manual bottle-squeeze method for postoperative healing after endoscopic sinonasal surgery (ESS).

Subjects and Method In this prospective randomized clinical trial, 29 patients were enrolled for nasal irrigation (NI) with either NOSSHA ${ }^{\circledR}$ (Womens Care Co., Ltd.) powered irrigation system $\left(\mathrm{NOSSHA}^{\circledR}\right.$ group, $\mathrm{n}=14$ ) or manual irrigation (control group, $\mathrm{n}=15$ ). Objective findings were evaluated using the modified Lund-Kennedy scores. Subjective outcomes were assessed using the total nasal endoscopic score (TNES), total nasal symptom score (TNSS), visual analog scale (VAS), and quality of life (QOL) questionnaires in each group at baseline, and $1,2,4,6$, and 8 weeks after ESS. We compared the postoperative changes between both groups.

Results The mean TNES of patients were significantly higher in the NOSSHA ${ }^{\circledR}$ group than in the control group ( $p=0.015)$; however, the improvement in TNES was achieved 2 weeks earlier in the NOSSHA ${ }^{\circledR}$ group. The improvement in TNES $(p<0.001)$ and TNSS $(p<0.001)$ was statistically significant in both groups. The improvement in QOL was statistically significant in the NOSSHA ${ }^{\circledR}(p<0.001)$ and control group $(p=0.007)$. The improvement in the TNSS and QOL was earlier in the NOSSHA ${ }^{\circledR}$ group by 4 and 7 weeks, respectively; no early improvement occurred in the NOSSHA ${ }^{\circledR}$ group for the VAS score.

Conclusion We validated the usefulness of postoperative NI using a powered device, which may be useful for patients who cannot tolerate manual NI.

Korean J Otorhinolaryngol-Head Neck Surg 2022;65(2):93-100

Keywords Device; Electricity; Sinusitis; Surgery; Therapy.

\section{Introduction}

Nasal irrigation (NI) plays a vital role in pre-and post-en-

This is an Open Access article distributed under the terms of the Creative Commons Attribution Non-Commercial License (https://creativecommons.org/licenses/by-nc/4.0) which permits unrestricted non-commercial use, distribution, and reproduction in any medium, provided the original work is properly cited. doscopic sinus surgery (ESS) to treat chronic rhinosinusitis (CRS). Moreover, a Cochrane review has shown that NI plays a role in improving symptoms and the quality of life (QOL). ${ }^{1)}$ NI serves as a non-invasive adjunctive postoperative treatment that reduces the antigens and biofilm and provides mucociliary clearance in the sinonasal mucosa. ${ }^{2)}$ Clinically, vari- 
ous irrigation methods have been used for physical cleaning and mucosal healing during the postoperative period after endoscopic sinus surgery.

Most studies on postoperative NI have been about saline composition or adjuvants using the classic manual bottlesqueeze method. ${ }^{3-5)}$ To date, normal saline solutions remain the standard formulation, with no significant difference between different solutions based on salt concentration. ${ }^{6}$ A recent cadaveric study comparing a pulsating device and the bottle-squeeze method for sinus penetration of the irrigant has concluded that the manual method is superior in native and operated conditions. ${ }^{7)}$ However, to the best of our knowledge, a paucity of information exists regarding the efficacy of powered irrigation devices in living patients after endoscopic sinus surgery. Moreover, there are several commercially available devices for postoperative NI. However, there is also little information in the literature verified by the systematic comparative trials.

This study compared a novel automatic device with the traditional manual method in an actual clinical setting. We compared the clinical distinction and patients' perspectives between the two methods at various postoperative periods using subjective questionnaires and postoperative endoscopic findings. We aimed to compare the efficacy of the powered and manual irrigation methods in postoperative care and validate the convenience based on patient perspectives.

\section{Subjects and Methods}

\section{Patients and study design}

This prospective randomized single-blinded study was conducted in a clinical trial setting. The inclusion criteria were: 1) adult patient ( $\geq 20$ years old) diagnosed with CRS; 2) refractory to optimal medical therapy and required endoscopic sinus surgery; 3) no history of sinonasal surgery. The exclusion criteria were: patients with 1) incomplete clinical data; 2) pregnancy or breastfeeding; 3) neoplasm; 4) uncontrolled systemic comorbidities; and 5) participation in other clinical trials within a month.

A total of 29 patients were included in the study and divided into two groups: 1) the NOSSHA ${ }^{\circledR}$ group (NI using a powered irrigation device, $n=14$ ), and 2 ) the control group (manual bottle-squeeze irrigation, $n=15$ ). The grouping was done by stratified randomization sampling. NOSSHA ${ }^{\circledR}$ (Womens Care Co., Ltd., Seoul, Korea) is a recently developed novel automatic sinonasal wash system that provides a constant volume and pres- sure, irrespective of the effort applied by the patient (Fig. 1). NOSSHA $^{\circledR}$ is one of the electrically operated high-volume and high-pressure devices. The device comprises the upper tank, the storage cradle, the nozzle in close contact with nostrils, and the washing tube. The maximum irrigation fluid volume is $250 \mathrm{~mL}$ which is the same as the manual bottle. The intensity of the irrigation pressure is controlled in 3 steps by pressing the button located in the center. The device is connected to the charging cradle for storage, and washing or sterilization is possible after separating the upper tank, the lower tank, and the nozzle. On the other hand, the control method- manual bottle-squeeze irrigation-is high-volume and low-pressure. The volume is the same in the NOSSHA ${ }^{\circledR}$ and control groups.

This study was approved by the Institutional Review Board of Konyang University Hospital (KYUH 2018-11-005-002). All participants provided written informed consent.

\section{Surgery and post-operative management}

The ESS was performed under general anesthesia by a single surgeon in our hospital. All surgical procedures were performed using the standard technique for ESS, as previously

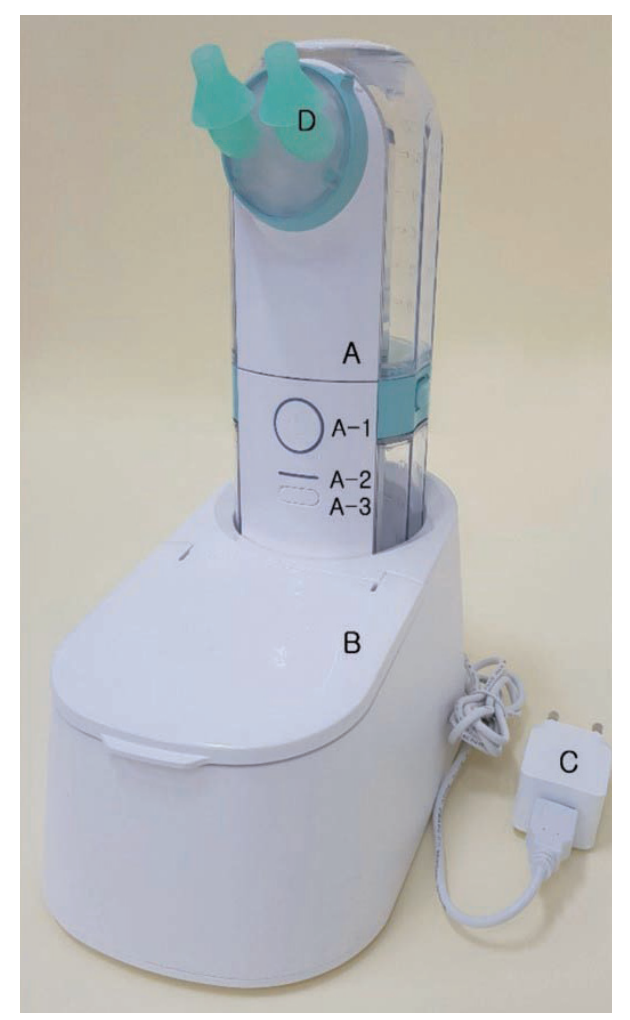

Fig. 1. Representative photograph of the NOSSHA ${ }^{\circledR}$ irrigation system (Womens Care Co., Ltd.; Seoul, Korea). The parts of the system are as follows: main body $(A)$, power switch $(A-1)$, intensity indicator (A-2), intensity control button (A-3), storage cradle (B), charger (C), and nozzle for the patient (D). 
reported, ${ }^{8)}$ and no iatrogenic complications were encountered. The wound was packed with the absorbable nasal dressing, Nasopore $^{\circledR}$ (Polyganics, Groningen, The Netherlands), and broad-spectrum oral antibiotics and mucolytics were prescribed in all patients. The absorbable nasal dressing was removed endoscopically at 2 days postoperatively; systemic corticosteroid was not prescribed while topical corticosteroid spray was used for all patients until 2 months after packing removal.

After the surgery, the patients in the NOSSHA ${ }^{\circledR}$ group used the powered irrigation device twice daily, while the control group used the manual bottle twice daily. We assessed the patients' status at baseline and 1,2, 4, 6, and 8 weeks postoperatively, using each item in the questionnaires in the outpatient office.

\section{Outcome measurements}

The participants underwent evaluations that included the total nasal endoscopic score (TNES), total nasal symptom score (TNSS), visual analog scale (VAS) score, and QOL questionnaires. The TNES was evaluated using nasal endoscopy (modified Lund-Kennedy score, as previously described). ${ }^{9)}$ The TNES was checked by two experienced otolaryngologists blinded to the grouping independently. Additionally, the patients also completed three patient-reported outcome measures, including TNSS, QOL, and VAS. The TNSS consisted of rhinorrhea, nasal congestion, nasal itching, and sneezing. Each group was evaluated using $0-3$ points, with a maximum of 12 points, and each group was analyzed at all points. ${ }^{10)}$ The QOL questionnaire evaluated the areas of a patients' QOL that were affected by rhinosinusitis. It consisted of five questions that allotted scores to rhinology symptoms caused by stimu1i. ${ }^{11)}$ The VAS is a reliable indicator of pain and was used to assess pain intensity after NI. The participants rated pain on a scale of 0 (no pain) to 10 (worst or intolerable pain). ${ }^{12)}$

\section{Statistical analysis}

General statistics are presented as mean \pm standard error of the mean for continuous data and frequency (\%) for categorical data. The baseline characteristics of the study participants were compared between the NOSSHA ${ }^{\circledR}$ and control group using the independent t-test, (interquartile range [Q1, Q3]) or Pearson's chi-square test, as appropriate. The outcome and the difference in the scores from the baseline were assessed using the mixed effect model for repeated-measures (MMRM) analysis with an unstructured covariance matrix. Furthermore, in the MMRM analysis, the differences in the baseline scores were also compared between the groups after adjusting for age, sex, and corresponding baseline score. All statistical analyses were conducted using IBM SPSS Statistics, version 26 (IBM Corp., Armonk, NY, USA) and GraphPad Prism Software Version 5.02 (GraphPad Software, San Diego, CA, USA). Statistical significance was declared in two-sided tests at a significance level of $\leq 0.05$.

\section{Results}

\section{Patient characteristics}

The baseline characteristics of the study participants are shown in Table 1. Among the 29 patients who participated, 14 were in the NOSSHA ${ }^{\circledR}$ group, and 15 were in the control group. The NOSSHA $^{\circledR}$ group comprised six women and eight men, whereas the control group comprised seven women and eight men. The mean age in the NOSSHA ${ }^{\circledR}$ group (40.43 years) was significantly lower than that in the control group (51.67 years) ( $p=0.041$ ). Comorbidity was not significantly different between the two groups. At the time of registration, the median (interquartile range [Q1, Q3]) of TNES was significantly higher among the patients in the NOSSHA ${ }^{\circledR}$ group $(7.00[5.75,8.00])$ than those in the control group (5.00 [4.00, 7.00]) $(p=0.014)$. However, the values of TNSS, QOL, and VAS in the NOSS$\mathrm{HA}^{\circledR}$ group $(5.00$ [3.75, 8.00], 19.00 [14.50, 23.25], and 5.50 $[3.50,7.25]$, respectively) were not significantly different from those in the control group (4.00 [1.00, 5.00], 13.00 [7.00, 18.00], and $5.00[2.00,6.00]$, respectively) at the time of registration ( $p=0.088, p=0.078$, and $p=0.493$, respectively).

\section{TNES and the difference in TNES according to follow-up period}

In the NOSSHA ${ }^{\circledR}$ group, the TNES significantly improved from $6.9 \pm 0.5$ to $0.6 \pm 0.3(p<0.001)$, and the improvement showed significance from the 2 nd week onward. In the control group, the values significantly improved from $5.3 \pm 0.4$ to $1.1 \pm 0.4$ over the study duration $(p<0.001)$; however, the improvement in TNES was statistically significant only after the 4th week (Fig. 2A and Supplementary Table 1A). This finding implied that a significant improvement in the TNES was achieved earlier in the NOSSHA ${ }^{\circledR}$ group than the control group.

The difference in the TNES at each follow-up visit was $0.3 \pm 0.6,2.1 \pm 0.6,4.4 \pm 0.6,6.2 \pm 0.6$, and $6.4 \pm 0.7$ in $\mathrm{NOSSHA}^{\circledR}$ group, respectively, and $0.4 \pm 0.6,0.7 \pm 0.6,2.2 \pm 0.6,3.3 \pm 0.5$, 
Table 1. Demographic characteristics of the study patients

\begin{tabular}{|c|c|c|c|}
\hline Characteristic & NOSSHA $^{\oplus}$ group $(n=14)$ & Control group $(n=15)$ & $p$-value \\
\hline Sex & & & 0.837 \\
\hline Female & $6(42.9)$ & $7(46.7)$ & \\
\hline Male & $8(57.1)$ & $8(53.3)$ & \\
\hline Age $(y r)$ & $40.43 \pm 4.41$ & $51.67 \pm 2.96$ & 0.041 \\
\hline \multicolumn{4}{|l|}{ Comorbid disease } \\
\hline Hypertension & $1(7.1)$ & $4(26.7)$ & 0.186 \\
\hline Diabetes mellitus & $0(0.0)$ & $2(13.3)$ & 0.259 \\
\hline Benign hepatic disease & $2(14.3)$ & $3(20.0)$ & 0.535 \\
\hline Asthma & $2(14.3)$ & $1(6.7)$ & 0.473 \\
\hline Benign thyroid nodule & $0(0.0)$ & $2(13.3)$ & 0.259 \\
\hline TNES & $7.00(5.75-8.00)$ & $5.00(4.00-7.00)$ & 0.014 \\
\hline TNSS & $5.00(3.75-8.00)$ & $4.00(1.00-5.00)$ & 0.088 \\
\hline Quality of life & $19.00(14.50-23.25)$ & $13.00(7.00-18.00)$ & 0.078 \\
\hline VAS & $5.50(3.50-7.25)$ & $5.00(2.00-6.00)$ & 0.493 \\
\hline
\end{tabular}

Data are presented as the $n(\%)$ or mean \pm SEM or median (IQR). Numerical quantitative data are presented as mean \pm SEM using the independent t-test and represented by median (Q1-Q3) using the Wilcoxon rank sum test. Categorical data are presented as frequency (\%) and were tested using the chi-square test. NOSSHA ${ }^{\circledast}$ irrigation system (Womens Care Co., Ltd.; Seoul, Korea). SEM, standard error of the mean; TNES; total nasal endoscopic score; IQR, interquartile range; TNSS; total nasal symptom score; VAS, visual analog scale

and $4.1 \pm 0.6$ in the control group, respectively. There was a statistically significant difference between the groups after 4 postoperative weeks ( $p=0.024$ ) (Fig. 3A and Supplementary Table $2 \mathrm{~A})$.

\section{TNSS and the difference in TNSS according to follow-up period}

The mean TNSS in the NOSSHA ${ }^{\circledR}$ group improved significantly from $5.7 \pm 0.9$ to $2.1 \pm 0.7$ ( $p<0.001)$, and the significance in the improvement was observed from the 4th week onward. In the control group, the TNSS improved significantly from $3.9 \pm 0.9$ to $1.3 \pm 0.4$ ( $p=0.014$ ), although a significant improvement was observed only at the 8th week (Fig. 2B and Supplementary Table 1B). This finding also implied that a significant improvement in the TNSS was achieved earlier in the NOSSHA ${ }^{\circledR}$ group than in the control group.

The difference in the changes in the TNSS was not statistically significant between the two groups at all postoperative time points ( $p=0.882$ ) (Fig. 3B and Supplementary Table 2B).

\section{QOL and the difference in QOL according to follow-up period}

The QOL in the NOSSHA ${ }^{\circledR}$ group improved significantly from $19.9 \pm 2.6$ to $5.9 \pm 1.8(p<0.001)$, and the significance in the improvement was observed from the 1st week. The QOL improved significantly only at the 8 th week in the control group; however, the overall improvement from $15.0 \pm 2.6$ to
$6.9 \pm 1.1$ was significant ( $p=0.007$ ) (Fig. $2 \mathrm{C}$ and Supplementary Table $1 \mathrm{C}$ ). This finding also implied that a significant improvement in QOL was achieved earlier in the NOSSHA $^{\circledR}$ group than in the control group.

The change in QOL gradually improved over time in both groups, although there was no statistically significant difference in the improvement between the two groups throughout the study period ( $p=0.057$ ). However, the changes in QOL from the baseline to the 1st and 6th week were significantly different between the two groups ( $p=0.031$ and 0.038 , respectively) (Fig. 3C and Supplementary Table 2C).

\section{VAS and the difference in VAS according to follow-up period}

Each VAS score in the NOSSHA ${ }^{\circledR}$ and control group improved significantly from $5.2 \pm 0.7$ and $4.7 \pm 0.6$, respectively, at registration to $0.4 \pm 0.2$ and $0.3 \pm 0.1$, respectively, at the end of the trial $(p<0.001)$. The VAS score began reducing equally from the 1st week in both groups (Fig. 2D and Supplementary Table 1D). Moreover, there was no significant difference in the score changes between the two groups $(p=0.407)$ (Fig. 3D and Supplementary Table 2D).

\section{Discussion}

NI has been recommended as an additional non-pharmacological therapy for patients with CRS and may be considered 

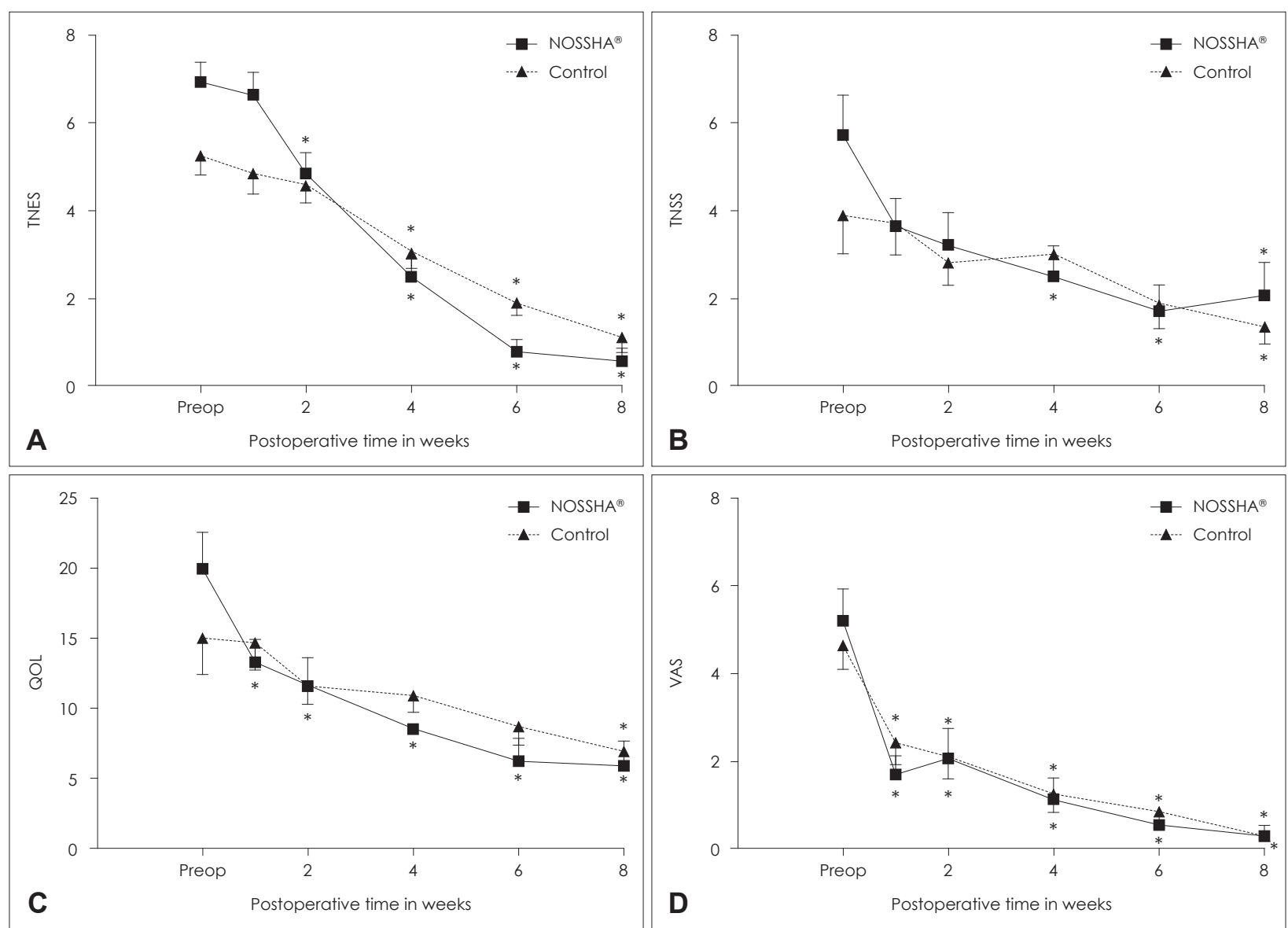

Fig. 2. Postoperative changes in the TNES, the TNSS, the QOL, and the VAS according to the groups. A: Postoperative changes in the TNES in the NOSSHA ${ }^{\circledR}$ group and the control group. B: Postoperative changes in the TNSS in the NOSSHA ${ }^{\circledR}$ group and the control group. C: Postoperative changes in the QOL score in the NOSSHA ${ }^{\circledR}$ group and the control group. D: Postoperative changes in the VAS score in the NOSSHA ${ }^{\circledR}$ group and control group. The values are expressed as meantstandard error of the mean. NOSSHA ${ }^{\circledR}$ irrigation system (Womens Care Co., Ltd.; Seoul, Korea). ${ }^{*} p<0.05$. TNES, total nasal endoscopic score; TNSS, total nasal symptom score; QOL, quality of life; VAS, visual analog scale.

a first-line treatment for this condition. ${ }^{13)}$ Moreover, based on a 2016 Cochrane review study, ${ }^{14)}$ NI has been strongly recommended as a potentially beneficial low-risk treatment option for CRS. Additionally, its application may have an indubitable role in the postoperative healing process. ${ }^{15)}$ A wide variety of irrigation methods have been investigated for clinical applications, including their components, hygiene status, and mode of delivery. ${ }^{16)}$ However, there is insufficient clarity regarding the tonicity and adjunctive solutions used in NI. ${ }^{17,18)}$ Moreover, the frequency and duration of NI in the literature are controversial. ${ }^{2,13)}$

However, regarding physical factors, the high-volume and low-pressure methods have been determined as the standard for sinonasal irrigant delivery. Typical high-volume and lowpressure delivery methods include manual squeeze bottles and gravity-dependent irrigation pots. One systematic review recommends high-volume devices for optimum paranasal sinus irrigant delivery after ESS. ${ }^{19)}$ They recommend using the lying-head-back or lateral head-low position with low-volume devices for patients who are intolerant to high-volume devices.

Recent cadaveric studies have validated the influence of surgical method and delivery position of irrigant on sinus penetration. $^{20,21)}$ Although high-volume and low-pressure devices are optimal for postoperative use, possible disadvantages NI using these devices include bothersome effort, uncomfortable sensation, burning, and Eustachian tube irritation. ${ }^{19)}$ Lowvolume devices, such as spray and nebulizers or high-pressure powered devices, may be alternatives for these patients.

Piromchai, et al. ${ }^{22)}$ have reported that low-volume and highpressure devices received significantly higher physicians' and patients' scores in a Thai multicenter survey. They also stated ease of learning as an advantage and retained fluid in the sinuses as a disadvantage.

In this study, a significant improvement was observed en- 

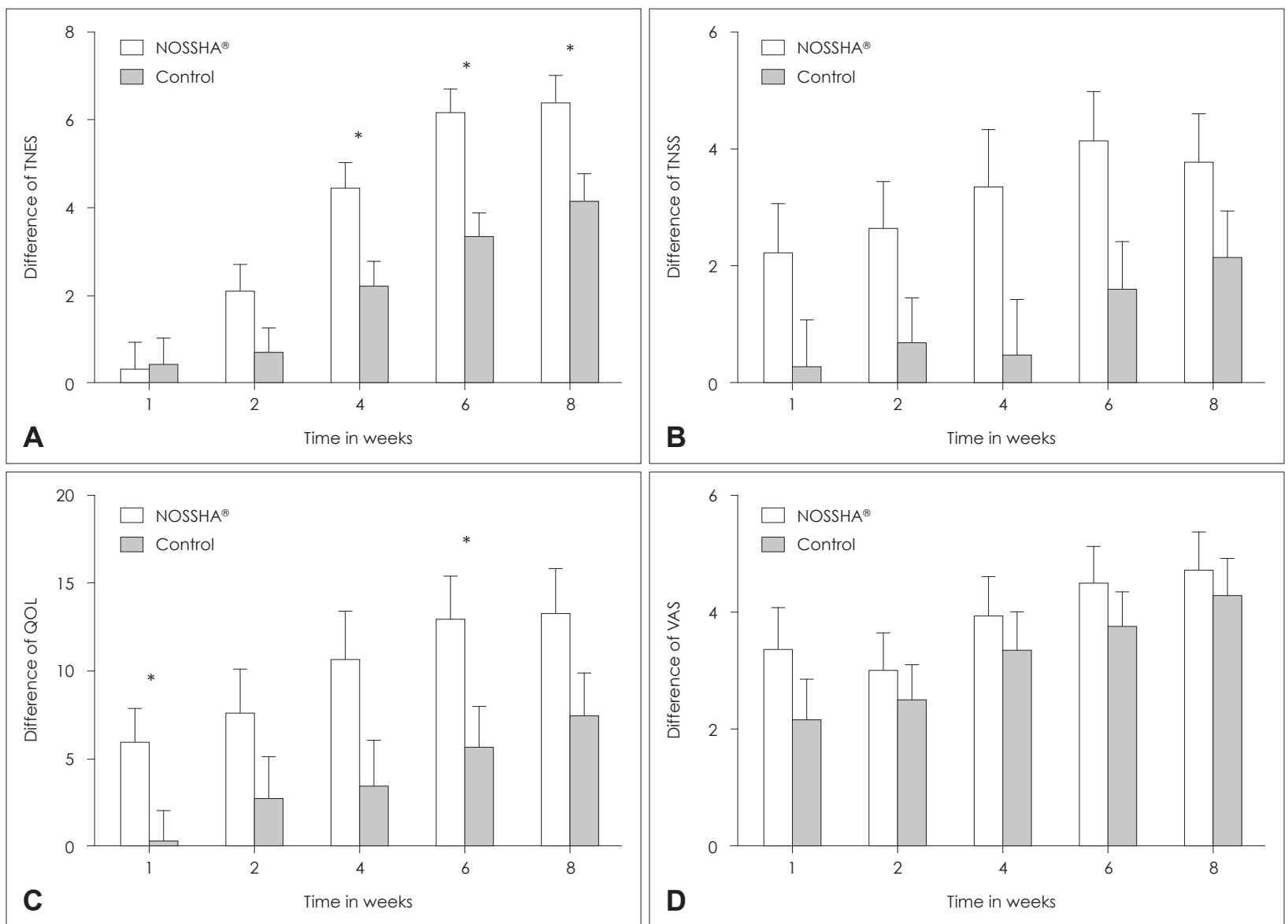

Fig. 3. Comparison of the differences in the TNES, the TNSS, the QOL, and the VAS between the groups from the baseline at the each time point. A: Comparison of TNES difference from the baseline between the NOSSHA ${ }^{\circledR}$ group and the control group. B: Comparison of TNSS difference from the baseline between the NOSSHA ${ }^{\circledR}$ group and the control group. C: Comparison of QOL difference from the baseline between the NOSSHA ${ }^{\circledR}$ group and control group. D: Comparison of VAS difference from the baseline between the NOSSHA ${ }^{\circledR}$ group and control group. The bar represents the mean of difference of each value from the baseline at each follow-up time point in each group. NOSSHA ${ }^{\circledR}$ irrigation system (Womens Care Co., Ltd.; Seoul, Korea). ${ }^{*} p<0.05$. TNES, total nasal endoscopic score; TNSS, total nasal symptom score; QOL, quality of life; VAS, visual analog scale.

doscopically, which was achieved earlier with the high-pressure powered device than with the manual bottle-squeeze method. Interestingly, this observation became more pronounced toward the end of the follow-up period. The powered irrigation system ensures consistent pressure, which is impossible with the manual squeeze method by living patients. Based on this finding, we assert that constant-pressure irrigation may provide greater mucosal healing over a late period than during the immediate postoperative period. From the patient's perspective, an improvement in the rhinology symptoms (TNSS) and pain (VAS) was not significantly different between the two groups. In contrast, the difference in the QOL was superior to the powered irrigation system. Additionally, through the TNSS and QOL measures, symptomatic improvement achieved with the use of the powered device was observed to be earlier than that with the manual bottle method.
The manual bottle-squeeze method requires unnecessary effort from the patients, whereas a powered irrigation device may be more convenient. In addition, by providing constant volume and pressure, a powered device can prevent eustachian tube irritation caused by applying unintended pressure. The irrigation device may be adjusted according to user convenience at different stages with a constant flow rate and pressure. This finding implies that the powered irrigation system may become an alternative therapeutic option for patient compliance.

There are similar NI devices that could be searched online. However, we could not find any evidence-based literature regarding these commercially available products. In the present study, the authors evaluated comparative clinical trials on powered NI and the golden standard treatment-the manual irrigation, based on subjective symptoms and endoscopic 
findings according to the postoperative periods. To the best of our knowledge, this is the first English article that tried to verify the clinical use of powered NI.

Regarding the side effects of this powered irrigation device, there was no evidence of iatrogenic otitis media due to the reflux from the eustachian tube or infections associated with nasal irrigation. However, there was a technical error at the outlet grounding part. The electrical short-circuit due to poor contact in the ground part of the power outlet was reported. There was no particular risk to the patient because the undesirable problem was at the electrical grounding area, not the area used by patients. The ground part should be plated with certainty, such as gold or silver, due to the electrical conductivity with saline solution. The device is not available for clinical use yet, but only for the research purpose at this time for technical reason. Further work would be needed for the technical correction because the device's safety has not been fully verified.

There are also some methodological limitations of this study. First, our study was limited by small sample size (approximately 15 patients per group). Second, there was a score gap between the two groups at the baseline. However, we adjusted this baseline discrepancy using the MMRM statistical method. The MMRM method can handle baselines after randomization in the clinical comparative study like this study. ${ }^{23)}$ Third, we evaluated the patients for a relatively short-term followup period ( 8 weeks). In contrast, the wound healing process in the sinonasal epithelium is usually completed within 11-14 weeks after ESS. ${ }^{24)}$ Fourth, we did not evaluate the patient's compliance. A future study using a larger number of patients with a long-term follow-up is needed to expand scientific knowledge and overcome the limitations of this study.

There are several strengths regarding the powered NI method. First, endoscopically, powered NI can provide a constant pressure, which is controlled in 3 steps. This helps faster and proper mucosal healing, particularly in the late postoperative period than manual bottle irrigation. Second, otologically, powered NI can avoid the iatrogenic otalgia or middle ear effusion from too forceful strength of irrigation by manual method. Third, subjectively, the electronic device provides clean and comfortable environments. The sterilization, soft nozzle to nostrils, without sink space for drain out, and without lying-head-down for irrigation would be another strength for powered NI device. In terms of drawbacks, the size of electronic devices is relatively larger than a classic bottle due to a power cord, operating tank, or irrigation tube. This could be a potential drawback for patients who travel often. In addition, the cost of electronic devices would be expensive than that of a plastic bottle. It may be five times more expensive than a classic bottle estimated online by similar products (approximately USD $\$ 100$ vs. USD \$20). The exact comparison could not be determined because NOSSHA ${ }^{\circledR}$ is not approved for clinical use yet.

In conclusion, NI with constant pressure provides rapid postoperative improvement. Using a powered device for NI may be suitable for patients who are unable to tolerate manual irrigation as an alternative therapeutic option. In addition, further research would be needed to verify the safety of electronic nasal irrigation technically and also clinically.

\section{Supplementary Materials}

The Data Supplement is available with this article at https://doi. org/10.3342/kjorl-hns.2021.00346.

\section{Acknowledgments}

This research was supported by a grant of the Korea Health Technology R\&D Project through the Korea Health Industry Development Institute (KHIDI), funded by the Ministry of Health \& Welfare, Republic of Korea (grant number: HI17C2412).

Seung Min In received a research grant from Womens Care Co., Ltd. No competing interests were reported for other authors. Womens Care Co., Ltd. had the contribution of product supply and no role of study conduction such as sample collection, data analysis and writing manuscript.

\section{Author Contribution}

Conceptualization: Ki-Il Lee, Seung Min In. Data curation: Ki-Il Lee, Sumin Son, Seung Ho Kim, Myeong Hee Kim. Formal analysis: Eunwoo Nam. Funding acquisition: Seung Min In. Investigation: Ki-Il Lee, Myeong Hee Kim. Methodology: Jong-Yeup Kim, Eunwoo Nam. Project administration: Seung Min In. Resources: Myeong Hee Kim. Software: Sumin Son, Seung Ho Kim. Supervision: Ki-Il Lee, Seung Min In. Validation: Ki-Il Lee, Eunwoo Nam. Visualization: Ki-Il Lee, Eunwoo Nam. Writing_original draft: Ki-Il Lee. Writing — review \& editing: Ki-Il Lee, Seung Min In.

\section{ORCIDs}

Seung Min In

https://orcid.org/0000-0002-1438-6915

Ki-Il Lee https://orcid.org/0000-0002-2069-7912

\section{REFERENCES}

1) Harvey R, Hannan SA, Badia L, Scadding G. Nasal saline irrigations for the symptoms of chronic rhinosinusitis. Cochrane Database Syst Rev 2007;3:CD006394.

2) Principi N, Esposito S. Nasal irrigation: An imprecisely defined medical procedure. Int J Environ Res Public Health 2017;14(5):516.

3) Low TH, Woods CM, Ullah S, Carney AS. A double-blind randomized controlled trial of normal saline, lactated Ringer's, and hypertonic saline nasal irrigation solution after endoscopic sinus surgery. Am J Rhinol Allergy 2014;28(3):225-31.

4) Kim DH, Kim Y, Lim IG, Cho JH, Park YJ, Kim SW, et al. Effect of postoperative xylitol nasal irrigation on patients with sinonasal diseases. Otolaryngol Head Neck Surg 2019;160(3):550-5. 
5) Huang ZZ, Chen XZ, Huang JC, Wang ZY, Li X, Chen XH, et al. Budesonide nasal irrigation improved Lund-Kennedy endoscopic score of chronic rhinosinusitis patients after endoscopic sinus surgery. Eur Arch Otorhinolaryngol 2019;276(5):1397-403.

6) Chen XZ, Feng SY, Chang LH, Lai XP, Chen XH, Li X, et al. The effects of nasal irrigation with various solutions after endoscopic sinus surgery: Systematic review and meta-analysis. J Laryngol Otol 2018;132(8):673-9.

7) Chen PG, Murphy J, Alloju LM, Boase S, Wormald PJ. Sinus penetration of a pulsating device versus the classic squeeze bottle in cadavers undergoing sinus surgery. Ann Otol Rhinol Laryngol 2017;126(1):9-13.

8) Kennedy DW. Functional endoscopic sinus surgery. Technique. Arch Otolaryngol 1985;111(10):643-9.

9) Psaltis AJ, Li G, Vaezeafshar R, Cho KS, Hwang PH. Modification of the Lund-Kennedy endoscopic scoring system improves its reliability and correlation with patient-reported outcome measures. Laryngoscope 2014;124(10):2216-23.

10) Restimulia L, Pawarti DR, Ekorini HM. The relationship between serum vitamin D levels with allergic rhinitis incidence and total nasal symptom score in allergic rhinitis patients. Open Access Maced J Med Sci 2018;6(8):1405-9.

11) Ni JS, Kompelli AR, Nguyen SA, Schlosser RJ, Clemmens C, Soler $\mathrm{ZM}$. The sinus and nasal quality of life survey (SN-5) in the management of pediatric chronic rhinosinusitis: A systematic review and meta-analysis. Int J Pediatr Otorhinolaryngol 2018;111:162-9.

12) Bruni M, Ryan LE, Tabor MH. Powered irrigation with suction evacuation for chronic rhinosinusitis in the office setting: A pilot study. Ear Nose Throat J 2018;97(4-5):E27-30.

13) Casale M, Moffa A, Cassano M, Carinci F, Lopez MA, Trecca EMC, et al. Saline nasal irrigations for chronic rhinosinusitis: From everyday practice to evidence-based medicine. An update. Int J Immunopathol Pharmacol 2018;32:2058738418802676.

14) Chong LY, Head K, Hopkins C, Philpott C, Glew S, Scadding G, et al. Saline irrigation for chronic rhinosinusitis. Cochrane Database Syst Rev 2016;4(4):CD011995.

15) Bastier PL, Lechot A, Bordenave L, Durand M, de Gabory L. Nasal irrigation: From empiricism to evidence-based medicine. A review. Eur Ann Otorhinolaryngol Head Neck Dis 2015;132(5):281-5.

16) Succar EF, Turner JH, Chandra RK. Nasal saline irrigation: A clinical update. Int Forum Allergy Rhinol 2019;9(S1):S4-8.

17) Nimsakul S, Ruxrungtham S, Chusakul S, Kanjanaumporn J, Aeumjaturapat $\mathrm{S}$, Snidvongs K. Does heating up saline for nasal irrigation improve mucociliary function in chronic rhinosinusitis? Am J Rhinol Allergy 2018;32(2):106-11.

18) Talbot AR, Herr TM, Parsons DS. Mucociliary clearance and buffered hypertonic saline solution. Laryngoscope 1997;107(4): 500-3.

19) Thomas WW 3rd, Harvey RJ, Rudmik L, Hwang PH, Schlosser RJ. Distribution of topical agents to the paranasal sinuses: An evidence-based review with recommendations. Int Forum Allergy Rhinol 2013;3(9):691-703.

20) Craig JR, Palmer JN, Zhao K. Computational fluid dynamic modeling of nose-to-ceiling head positioning for sphenoid sinus irrigation. Int Forum Allergy Rhinol 2017;7(5):474-9.

21) Halderman AA, Stokken J, Sindwani R. The effect of middle turbinate resection on topical drug distribution into the paranasal sinuses. Int Forum Allergy Rhinol 2016;6(10):1056-61.

22) Piromchai P, Puvatanond C, Kirtsreesakul V, Chaiyasate S, Thanaviratananich S. Effectiveness of nasal irrigation devices: A Thai multicentre survey. PeerJ 2019;7:e7000.

23) Dinh P, Yang P. Handling baselines in repeated measures analyses with missing data at random. J Biopharm Stat 2011;21(2):326-41.

24) Xu G, Jiang H, Li H, Shi J, Chen H. Stages of nasal mucosal transitional course after functional endoscopic sinus surgery and their clinical indications. ORL J Otorhinolaryngol Relat Spec 2008;70(2):118-23. 
Supplementary Table 1A. Postoperative change in total nasal endoscopic score in both groups

\begin{tabular}{|c|c|c|c|c|c|c|c|c|}
\hline & \multicolumn{4}{|c|}{ NOSSHA $^{\circledR}$ group $(n=14)$} & \multicolumn{4}{|c|}{ Control group $(n=15)$} \\
\hline & Mean & SEM & $\begin{array}{c}\text { p-value* } \\
\text { (ref. baseline) }\end{array}$ & $\begin{array}{l}\text { p-value }{ }^{\dagger} \\
\text { (overall) }\end{array}$ & Mean & SEM & $\begin{array}{c}\text { p-value* } \\
\text { (ref. baseline) }\end{array}$ & $\begin{array}{l}\text { p-value }{ }^{\dagger} \\
\text { (overall) }\end{array}$ \\
\hline Week 0 & 6.929 & 0.462 & & $<0.001$ & 5.267 & 0.441 & & $<0.001$ \\
\hline Week 1 & 6.643 & 0.520 & $>0.999$ & & 4.867 & 0.487 & $>0.999$ & \\
\hline Week 2 & 4.857 & 0.467 & 0.042 & & 4.600 & 0.412 & $>0.999$ & \\
\hline Week 4 & 2.500 & 0.389 & $<0.001$ & & 3.067 & 0.384 & 0.001 & \\
\hline Week 6 & 0.786 & 0.281 & $<0.001$ & & 1.933 & 0.316 & $<0.001$ & \\
\hline Week 8 & 0.571 & 0.291 & $<0.001$ & & 1.133 & 0.363 & $<0.001$ & \\
\hline
\end{tabular}

The outcome scores, assessed using the mixed-effect model for repeated measures analysis with an unstructured covariance matrix. NOSSHA ${ }^{\circledast}$ irrigation system (Womens Care Co., Ltd.; Seoul, Korea). *the score at each follow-up visit was compared to the baseline score for the post-hoc analysis with Bonferroni correction; the overall test, compared to the outcome scores among follow-up visits within each model. SEM, standard error of the mean; ref., reference

Supplementary Table 1B. Postoperative change in total nasal symptom score in both groups

\begin{tabular}{|c|c|c|c|c|c|c|c|c|}
\hline & \multicolumn{4}{|c|}{$\operatorname{NOSSHA}^{\circledR}(n=14)$} & \multicolumn{4}{|c|}{ Control $(n=15)$} \\
\hline & Mean & SEM & $\begin{array}{c}p \text {-value* } \\
\text { (ref. baseline) }\end{array}$ & $\begin{array}{l}p \text {-value }{ }^{\dagger} \\
\text { (overall) }\end{array}$ & Mean & SEM & $\begin{array}{c}\text { p-value* } \\
\text { (ref. baseline) }\end{array}$ & $\begin{array}{l}p \text {-value }{ }^{\dagger} \\
\text { (overall) }\end{array}$ \\
\hline Week 0 & 5.714 & 0.904 & & $<0.001$ & 3.867 & 0.856 & & 0.014 \\
\hline Week 1 & 3.643 & 0.617 & 0.197 & & 3.733 & 0.746 & $>0.999$ & \\
\hline Week 2 & 3.214 & 0.728 & 0.073 & & 2.800 & 0.500 & 0.731 & \\
\hline Week 4 & 2.500 & 0.701 & 0.049 & & 3.000 & 0.535 & $>0.999$ & \\
\hline Week 6 & 1.714 & 0.588 & 0.001 & & 1.867 & 0.559 & 0.195 & \\
\hline Week 8 & 2.071 & 0.745 & 0.003 & & 1.333 & 0.374 & 0.040 & \\
\hline
\end{tabular}

Outcome scores were assessed using the mixed effect model for repeated-measures analysis with an unstructured covariance matrix. NOSSHA ${ }^{\circledR}$ irrigation system (Womens Care Co., Ltd.; Seoul, Korea). *the score at each follow-up visit was compared to the baseline score for the post-hoc analysis with Bonferroni correction; ${ }^{\dagger}$ the overall test compared outcome scores among follow-up visits within each model. SEM, standard error of the mean; ref., reference

Supplementary Table 1C. Postoperative change in quality of life in both groups

\begin{tabular}{|c|c|c|c|c|c|c|c|c|}
\hline & \multicolumn{4}{|c|}{ NOSSHA $^{\circledast}(n=14)$} & \multicolumn{4}{|c|}{ Control $(n=15)$} \\
\hline & Mean & SEM & $\begin{array}{c}p \text {-value* } \\
\text { (ref. baseline) }\end{array}$ & $\begin{array}{l}p \text {-value }{ }^{\dagger} \\
\text { (overall) }\end{array}$ & Mean & SEM & $\begin{array}{c}\text { p-value* } \\
\text { (ref. baseline) }\end{array}$ & $\begin{array}{l}\text { p-value }{ }^{\dagger} \\
\text { (overall) }\end{array}$ \\
\hline Week 0 & 19.929 & 2.640 & & $<0.001$ & 15.000 & 2.589 & & 0.007 \\
\hline Week 1 & 13.214 & 1.665 & 0.026 & & 14.667 & 1.968 & $>0.999$ & \\
\hline Week 2 & 11.571 & 2.013 & 0.015 & & 11.600 & 1.323 & $>0.999$ & \\
\hline Week 4 & 8.500 & 2.083 & 0.003 & & 10.867 & 1.171 & 0.660 & \\
\hline Week 6 & 6.214 & 1.601 & $<0.001$ & & 8.667 & 1.279 & 0.132 & \\
\hline Week 8 & 5.857 & 1.824 & $<0.001$ & & 6.867 & 1.077 & 0.044 & \\
\hline
\end{tabular}

Outcome scores were assessed using the mixed effect model for repeated-measures analysis with an unstructured covariance matrix. NOSSHA ${ }^{\circledR}$ irrigation system (Womens Care Co., Ltd.; Seoul, Korea). *the score at each follow-up visit was compared to the baseline score for the post-hoc analysis with Bonferroni correction; ${ }^{\text {the }}$ overall test compared outcome scores among follow-up visits within each model. SEM, standard error of the mean; ref., reference

Supplementary Table 1D. Postoperative change in visual analog scale in both groups

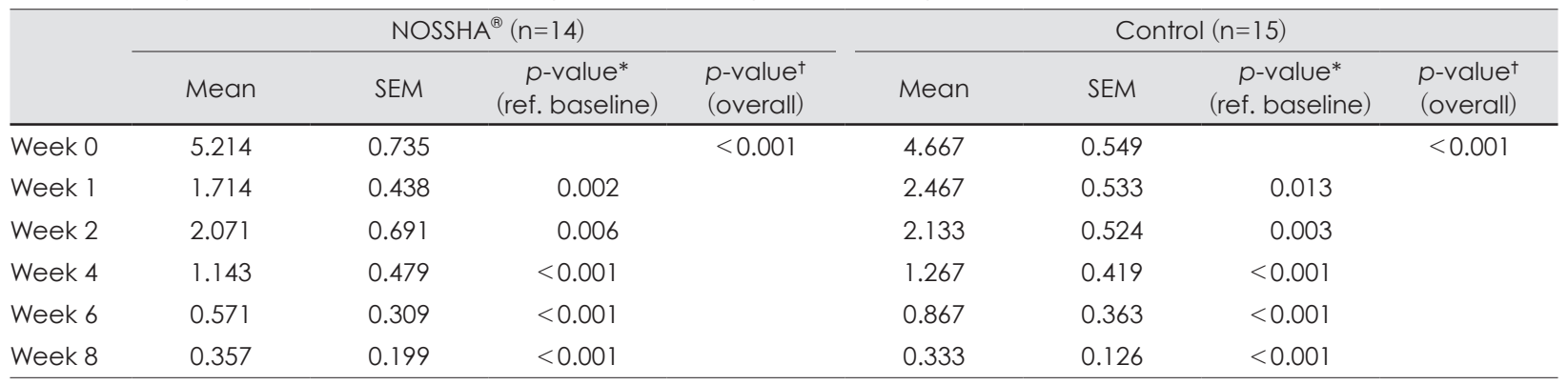

Outcome scores were assessed using the mixed effect model for repeated-measures analysis with an unstructured covariance matrix. NOSSHA ${ }^{\circledR}$ irrigation system (Womens Care Co., Ltd.; Seoul, Korea). *the score at each follow-up visit was compared to the baseline score for the post-hoc analysis with Bonferroni correction; the overall test compared outcome scores among follow-up visits within each model. SEM, standard error of the mean; ref., reference 
Supplementary Table 2A. Comparison of TNES changes between two groups at each time point

\begin{tabular}{|c|c|c|c|c|c|c|}
\hline & NOSSH & $\mathrm{n=14)}$ & Cont & $=15)$ & p-value* & $p$-value ${ }^{\dagger}$ \\
\hline & Mean & SEM & Mean & SEM & (within FU visit) & (overall) \\
\hline Week 1 & 0.290 & 0.628 & 0.396 & 0.606 & 0.904 & 0.024 \\
\hline Week 2 & 2.075 & 0.607 & 0.663 & 0.587 & 0.100 & \\
\hline Week 4 & 4.432 & 0.577 & 2.196 & 0.557 & 0.007 & \\
\hline Week 6 & 6.147 & 0.554 & 3.330 & 0.536 & 0.001 & \\
\hline Week 8 & 6.361 & 0.652 & 4.130 & 0.630 & 0.017 & \\
\hline
\end{tabular}

After adjusting age, sex and baseline TNES, TNES changes from baseline were assessed in the mixed effect model for repeated measures (MMRM) analysis with an unstructured covariance matrix. NOSSHA ${ }^{\circledast}$ irrigation system (Womens Care Co., Ltd.; Seoul, Korea). *a post-hoc analysis compared TNES changes from baseline between two models at each follow-up visit; †the overall test compared TNES changes from baseline between the two models. TNES, total nasal endoscopic score; FU, follow-Up

Supplementary Table 2B. Comparison of TNSS changes between two groups at each time point

\begin{tabular}{|c|c|c|c|c|c|c|}
\hline & NOSSH & $\mathrm{n}=14)$ & Con & =15) & p-value* & $p$-value ${ }^{\dagger}$ \\
\hline & Mean & SEM & Mean & SEM & (within FU visit) & (overall) \\
\hline Week 1 & 2.217 & 9.319 & 0.258 & 12.870 & 0.902 & 0.882 \\
\hline Week 2 & 2.646 & 9.319 & 0.675 & 12.870 & 0.901 & \\
\hline Week 4 & 3.360 & 9.321 & 0.475 & 12.871 & 0.856 & \\
\hline Week 6 & 4.146 & 9.318 & 1.608 & 12.869 & 0.873 & \\
\hline Week 8 & 3.789 & 9.319 & 2.142 & 12.869 & 0.917 & \\
\hline
\end{tabular}

After adjusting age, sex and baseline TNSS, TNSS changes from baseline were assessed in the mixed effect model for repeated measures analysis with an unstructured covariance matrix. NOSSHA ${ }^{\circledR}$ irrigation system (Womens Care Co., Ltd.; Seoul, Korea). *a post-hoc analysis compared TNSS changes from baseline between two models at each follow-up visit; †the overall test compared TNSS changes from baseline between the two models. TNSS, total nasal symptom score; SEM, standard error of the mean; FU, follow-up

Supplementary Table 2C. Comparison of QOL changes between two groups at each time point

\begin{tabular}{|c|c|c|c|c|c|c|}
\hline & \multicolumn{2}{|c|}{ NOSSHA $^{\oplus}$ group $(n=14)$} & \multicolumn{2}{|c|}{ Control group $(n=15)$} & \multirow{2}{*}{$\begin{array}{c}\text { p-value* } \\
\text { (within FU visit) }\end{array}$} & \multirow{2}{*}{$\begin{array}{l}p \text {-value }{ }^{\dagger} \\
\text { (overall) }\end{array}$} \\
\hline & Mean & SEM & Mean & SEM & & \\
\hline Week 1 & 5.984 & 1.874 & 0.323 & 1.729 & 0.031 & 0.057 \\
\hline Week 2 & 7.627 & 2.537 & 2.743 & 2.391 & 0.168 & \\
\hline Week 4 & 10.699 & 2.744 & 3.477 & 2.596 & 0.063 & \\
\hline Week 6 & 12.984 & 2.483 & 5.677 & 2.338 & 0.038 & \\
\hline Week 8 & 13.341 & 2.557 & 7.477 & 2.411 & 0.103 & \\
\hline
\end{tabular}

After adjusting age, sex and baseline QOL, QOL changes from baseline were assessed in the mixed effect model for repeated measures analysis with an unstructured covariance matrix. NOSSHA ${ }^{\circledR}$ irrigation system (Womens Care Co., Ltd.; Seoul, Korea). *a post-hoc analysis compared QOL changes from baseline between two models at each follow-up visit; †the overall test compared QOL changes from baseline between the two models. QOL, quality of life; SEM, standard error of the mean; FU, follow-up

Supplementary Table 2D. Comparison of VAS changes between two groups at each time point

\begin{tabular}{|c|c|c|c|c|c|c|}
\hline & \multicolumn{2}{|c|}{ NOSSHA $^{\circledast}$ group $(n=14)$} & \multicolumn{2}{|c|}{ Control group $(n=15)$} & \multirow{2}{*}{$\begin{array}{c}\text { p-value* } \\
\text { (within FU visit) }\end{array}$} & \multirow{2}{*}{$\begin{array}{l}\text { p-value } \\
\text { (overall) }\end{array}$} \\
\hline & Mean & SEM & Mean & SEM & & \\
\hline Week 1 & 3.369 & 0.718 & 2.162 & 0.690 & 0.231 & 0.407 \\
\hline Week 2 & 3.012 & 0.640 & 2.496 & 0.614 & 0.563 & \\
\hline Week 4 & 3.940 & 0.676 & 3.362 & 0.649 & 0.540 & \\
\hline Week 6 & 4.512 & 0.624 & 3.762 & 0.598 & 0.389 & \\
\hline Week 8 & 4.726 & 0.663 & 4.296 & 0.636 & 0.642 & \\
\hline
\end{tabular}

After adjusting age, sex and baseline VAS, VAS changes from baseline were assessed in the mixed effect model for repeated measures analysis with an unstructured covariance matrix. NOSSHA ${ }^{\oplus}$ irrigation system (Womens Care Co., Ltd.; Seoul, Korea). *a post-hoc analysis compared VAS changes from baseline between two models at each follow-up visit; †the overall test compared VAS changes from baseline between the two models. VAS, visual analog scale; SEM, standard error of the mean; FU, follow-Up 